\title{
EFFECT OF METHOXYFLURANE ON RENAL CONCENTRATING POWER
}

\author{
T.J. McCaughey, M. Dunkley, M.S. Batra, and Carol Thomson
}

THE REPORT of Crandell, ${ }^{1}$ at first rather neglected, and the later more insistent work of $\mathrm{Mazze}^{2}$ have shown that methoxyflurane can cause a loss of renal concentrating power. Inorganic fluoride ions released in the breakdown of methoxyflurane appear to cause renal tubular damage though the levels of fluoride ion associated with renal toxicity have been thought to be higher than those associated with "light" anaesthesia. Hetrick et $a l^{3}$ found no renal damage in a small prospective study in patients under "light" anaesthesia.

Our objective was to study prospectively the effect of three dosage levels of methoxyflurane anaesthesia on kidney concentrating ability; and to see, if a loss of concentrating ability occurs, whether this effect shows a significant positive correlation with the level of serum inorganic fluoride ion.

Operations included in the study were divided into three groups to give three dosage levels of methoxyflurane. These groups are (a) anaesthetics lasting 30 to 75 minutes (Group A), (b) anaesthetics lasting between 76 and 120 minutes (Group B), (c) anaesthetics lasting between 121 and 180 minutes (Group C).

Fifty patients were studied in each group, 25 methoxyflurane and 25 a control anaesthetic. The following patients were excluded: (1) those over 65 years of age; (2) those suffering from renal disease; (3) diabetics; (4) the grossly obese, defined as patients weighing more than 25 pounds over ideal body weight (Metropolitan Life Table); (5) patients with terminal or incapacitating diseases; (6) patients receiving tetracycline, antihypertensive or diuretic drugs; (7) patients undergoing operations on the kidneys or any likely to compromise the blood supply to the kidneys.

A specially trained research nurse (C.T.) selected the 50 patients for each group and allotted them at random to the methoxyflurane or control groups.

Anaesthetic procedure. The anaesthetics were given by 22 anaesthetists, 11 being staff and 11 senior fellows. The following guidelines were applied:

\section{Methoxyfurane group}

(1) No preanaesthetic medication was given;

(2) atropine $0.6 \mathrm{mg}$ given intravenously one minute prior to induction;

(3) induction with thiopentone $3-5 \mathrm{mg} / \mathrm{kg}$ body weight;

(4) muscle relaxants (a) succinylcholine $1 \mathrm{mg} / \mathrm{kg}$ intravenously for intubation; (b) d-tubocurarine as necessary;

(5) maintenance $(a)$ nitrous oxide, oxygen 50:50 at 5 litres/min total flow rate; (b) methoxyflurane as required;

(6) tracheal intubation and controlled respiration if required.

From Department of Anaesthesia, Montreal General Hospital and McGill University, Montreal, P.Q. 
Control group. As for the previous group, but a narcotic anaesthetic was substituted for methoxyflurane.

Machines and Circuits. For the study group anaesthetists used a special machine with a methoxyflurane vaporizer (Pentec) checked for accuracy and there was no other vaporizer on the machine. To avoid contamination from previous anaesthetics and because of the high solubility of methoxyflurane in rubber, fresh baralyme and disposable breathing circuits of nonabsorbing plastic were used. For the control group a machine without any vaporizers was used, again with fresh baralyme and disposable circuits.

Concentrations used. More to make anaesthetists think of the principles of uptake and distribution of methoxyflurane than to establish uniformity of administration, which was considered impossible to achieve and clinically undesirable, all participating anaesthetists received a brochure in which Lowe described a technique of administering methoxyflurane. ${ }^{4}$ All anaesthetists kept records of flow rates, vaporizer concentrations of methoxyflurane and times at which concentrations were changed. From these data it was possible to calculate the actual amounts of methoxyflurane vaporized and to compare them with the ideal amounts described by Lowe.

While some anaesthetists erred on the heavy side of Lowe's ideal dose, in fact most considered that Lowe's instructions resulted in the administration of more methoxyflurane than they considered necessary. It was therefore emphasized that anaesthesia was to be given "secundum artem" i.e. as the patient's condition seemed to demand. The actual total amounts vaporized were compared with Lowe's recommendations.

Intravenous Fluids and Blood. The instructions were: (1) To replace loss of over 15 per cent of predicted blood volume with blood; (2) To administer lactated Ringer's solution during the operation at the rate of $7 \mathrm{ml} / \mathrm{kg} /$ hour to compensate for third space losses; (3) To record accurately all blood and fluids given and lost.

Figure 1

\begin{tabular}{|c|c|c|c|c|c|}
\hline \\
\hline & & & & & \\
\hline \multicolumn{6}{|c|}{$\begin{array}{l}\text { Schedule of Study Period } \\
\text { 1 }\end{array}$} \\
\hline & ${ }^{\circ} 2$ & ${ }^{\circ} 2$ & & ${ }^{\circ} 2$ & ${ }^{\circ} 2$ \\
\hline & 3 & & & & ${ }^{\circ} 3$ \\
\hline & ${ }^{\circ} 4$ & ${ }^{\circ} 4$ & & 4 & ${ }^{\circ} 4$ \\
\hline & ${ }^{\circ} 5$ & & & & ${ }^{\circ} 5$ \\
\hline & ${ }^{\circ} 6$ & ${ }^{\circ} 6$ & ${ }^{\circ} 6$ & ${ }^{\circ} 6$ & \\
\hline DAY & 0 & 1 & 2 & 3 & 4 \\
\hline
\end{tabular}

\footnotetext{
1 - Concentrating ability test

$\circ 2$ - Serum creatinine, BUN

3-Serum osmolality

${ }^{\circ} 4$ - Serum fluoride

5 - Urinalysis

-6 - 24-hour intake/output measurement

Remarks - Day 0 is the day of surgery, 1 to 5 are successive days postoperatively.
} 
Urine concentrating test. This is taken as the urine osmolality after a 12-hour overnight fast from food and fluids. Patients were fasted from 7 p.m. on the preoperative evening. At 6 a.m. on the morning of operation they emptied their bladders and at 7 a.m., or as soon thereafter as possible they voided, a specimen of urine was collected and the osmolality was measured. The procedure was repeated postoperatively on the evening of day 4 and the morning of day 5 . Since operations were often of a major kind and intravenous fluids were needed postoperatively it was found that day 5 was the first day on which it was practical to do a urine concentrating test on all patients.

Serum fluorides: Serum samples from venous blood were stored under refrigeration and examined within 3 or 4 days. Serum inorganic fluoride levels were measured by means of an Orion Model of 96-09 Combination Fluoride Electrode and Orion Model 401 Specific Ion Meter. Samples were diluted with an equal volume of Orion TISAB buffer before measurement and were stirred magnetically during the measurement. Blood was taken from patients on the operating table before induction to serve as a baseline. In the first few patients a number of blood samples were taken during anaesthesia to ascertain whether levels of serum fluoride reached a peak during operation. Methoxyflurane caused serum fluoride levels to rise promptly after induction and to continue to rise during the anaesthetic without suggestion of a peak or plateau. A single sample was therefore taken at the end of the operation in all subsequent patients and this value was taken as that for the day of operation (day 0 ).

In the first 30 patients serum fluoride levels were measured on the first, second, third and fifth postoperative days. When the results were examined, it was found that values for serum fluoride fall after day one (the day after operation) and consequently, in the remaining 120 patients, these measurements were done on days 1,3 , and 5 only. The study was designed to compare differences in urine osmolality before and after methoxyflurane and a control anaesthetic and to correlate differences in the methoxyflurane group with levels of serum fluorides. The remainder of the data were collected as baseline measurements and to detect gross abnormalities of kidney function. These were serum creatinine and blood urea nitrogen, serum osmolality, urinalysis and 24-hour fluid intake and output to detect the typical lesion of methoxyflurane and to assess the adequacy of fluid replacement. Nurses recorded the time at which patients were able to tolerate fluids by mouth. In all patients intravenous fluids had to be discontinued by the fourth day in order to perform a concentrating test.

Fifty-six patients were rejected from the study for the following reasons:

1. Urine osmolality too low to indicate adequate preoperative concentrating power (below an arbitrary figure of $500 \mathrm{mOS} / \mathrm{L}$ ), eight patients;

2. the anaesthetist departed from the recommended technique, six patients;

3. patients left hospital before tests completed, 14;

4. excess of number of patients required, eight;

5. miscellaneous: operation cancelled, abnormal blood chemistry pre-operatively, incomplete data, unable to tolerate overnight fast on day $4-5$, anaesthetist or patient opted for another technique, patients refused to cooperate with blood sampling postoperatively, 19. 
On completion of the study the data on one patient were removed before analysis. This patient (number 16 in Group C, methoxyflurane) had a preoperative urine osmolality after overnight fluid deprivation of $1600 \mathrm{mOS} / \mathrm{L}$ which on discussion with out advisors in nephrology was considered physiologically impossible and probably due to contamination. Group C. methoxyflurane, therefore contained 24 patients for analysis instead of 25 .

\section{RESULts*}

\section{Relationship between loss of kidney concentrating power and serum fluorides}

A stepwise multiple regression was done to test the relationship of loss of kidney concentrating power (the response variable) to postoperative serum fluoride level and drug dose (the stimulus variables) in each of the three groups A, B and C.

Loss of kidney concentrating power was measured as the difference in urine osmolalities on day 0 and day 5 . Serum fluoride levels were measured immediately after operation, and again on days 1, 3 and 5 after operation. The mechanics of the regression analysis are described in a footnote.

Interpretation. These analyses were interpreted to mean that if one gives methoxyflurane over the ranges of duration in this study one can be reasonably sure that there will be a loss of concentrating power as compared with a narcoticnitrous oxide relaxant technique $(p=0.065)$; that there was a strong influence on loss of concentrating power exerted by duration when methoxyflurane and the control anaesthetic are considered together $(p=0.039)$; that the influence of duration on loss of concentrating power in the methoxyflurane group compared with the control group is worth considering, although it is statistically not significant at the 5 per cent level $(p=0.19)$. We are left with the distinct feeling that duration of anaesthetic has an influence on loss of concentrating power both in its own right and because of longer methoxyflurane exposure.

\section{Does $40 \mu M / L$ represent a critical serum level of inorganic fluoride?}

Because a suggestion has been made that a serum fluoride level of $40 \mu \mathrm{M} / \mathrm{L}$ may represent a critical point in its effect on kidney concentrating power, loss of concentrating power was compared in two sub-groups of the patients on methoxyflurane: Those for whom max SEFL was less than 40 and those for whom max SEFL was more than 40 . The residuals calculated previously were used for this comparison. The difference between the two groups was not significant $(p>0.10)$. Again this can probably be attributed to the very large variation within each group.

\section{Discussion}

In $1931^{5}$ Goldemberg reported a syndrome resembling diabetes insipidus in thyrotoxic patients treated with intravenous sodium fluoride, $100 \mathrm{mg}$ daily. In 10 to 15 days he noted that the daily urinary output had risen to 4 to 5 litres. Taves et al., ${ }^{6}$ making a number of general assumptions have calculated that under those circumstances plasma fluoride would have reached $60 \mu \mathrm{M} /$ litre. Taves et al. ${ }^{6}$

'Table I summarizes the operations, age ranges and sex distribution in the Groups. The complete results fo: all 150 patients may be had by applying to the lead author. 
TABLE I

\begin{tabular}{|c|c|c|c|c|c|c|c|}
\hline & \multirow[b]{2}{*}{ Total } & \multirow[b]{2}{*}{ Age Range } & \multicolumn{2}{|c|}{ Sex } & \multicolumn{3}{|c|}{ Type of Surgery } \\
\hline & & & Male & Female & General & Orthopedic & ENT \\
\hline $\begin{array}{l}\text { Group } A_{1} \\
\text { Group } A_{2} \\
\text { Group } B_{1} \\
\text { Group } B_{2} \\
\text { Group } C_{1} \\
\text { Group } C_{2}\end{array}$ & $\begin{array}{l}25 \\
25 \\
25 \\
25 \\
25 \\
25\end{array}$ & $\begin{array}{l}19-65 \\
17-62 \\
27-64 \\
16-64 \\
18-63 \\
18-65\end{array}$ & $\begin{array}{r}9 \\
10 \\
7 \\
8 \\
14 \\
14\end{array}$ & $\begin{array}{l}16 \\
15 \\
18 \\
17 \\
11 \\
11\end{array}$ & $\begin{array}{r}18 \\
18 \\
15 \\
17 \\
9 \\
10\end{array}$ & $\begin{array}{l}7 \\
7 \\
8 \\
7 \\
8 \\
7\end{array}$ & $\begin{array}{l}0 \\
0 \\
2 \\
1 \\
8 \\
8\end{array}$ \\
\hline
\end{tabular}

$A_{1}$ Methoxyflurane for 30-75 minutes.

$\mathrm{B}_{1}$ Methoxyflurane for 76-120 minutes.

$C_{1}$ Methoxyflurane for 120-180 minutes.
$C_{2}$ Control

have reported a level of $275 \mu \mathrm{M} / \mathrm{L}$ in a very obese patient who developed polyuric renal failure after four hours of methoxyflurane anaesthesia. That patient died 12 weeks postoperatively.

Whitford and Taves ${ }^{7}$ have administered fluoride intravenously to rats and have produced diuresis equivalent to 180 per cent of control values by raising serum fluoride levels to $50 \mu \mathrm{M} / \mathrm{L}$. Chronic fluoride poisoning in rats over a period of months results in diminished growth, malformed teeth, loss of body fat, polydipsia, polyuria with a low urine specific gravity, a lowered renal threshold for sugar and small, shrunken kidneys showing damage to vessels, glomeruli and tubules. ${ }^{8}$

It is not known how fluoride causes a loss of renal concentrating power. The lesion is thought to affect tubular transport and the function of the collecting ducts. A possible loss of medullary hypertonicity has been suggested but has not been documented. Fluoride is an enzymatic poison. Ferguson ${ }^{9}$ found that fluoride would lower alkaline phosphatase in volunteers. He then performed three surveys on the effect of fluoridation of drinking water at levels at or below 1 part per million ( $1 \mathrm{ppm}$ ). He observed a fall in alkaline phosphatase after fluoridation and a recovery to previous levels after some weeks. When the level of fluoridation was raised after recovery (but still to a level below $1 \mathrm{ppm}$ ) alkaline phosphatase levels fell again and again recovered after some weeks. Nobody in the survey seemed to suffer any ill health as a result of decrease of serum alkaline phosphatase. The mechanism by which alkaline phosphatase was lowered is not known. It is apparently not due to a direct action of fluoride on alkaline phosphatase in the plasma, since it cannot be produced in vitro, at least at the serum values encountered.

There is ample evidence then of the acute and chronic toxicity of fluoride on concentrating ability of the kidney. We have attempted to determine whether there is a loss of concentrating power in ordinary anaesthetic exposures with methoxyflurane as compared with a standard narcotic-nitrous oxide relaxant technique and whether this loss was associated with high serum levels of inorganic fluoride.

From our results it is clear that serum levels of inorganic fluoride correlate with loss of kidney concentrating power. There is evidence that there will be a greater loss of concentrating power with the use of methoxyflurane than with the control anaesthetic ( $\mathrm{p}$ values $=0.069$ ).

There was no significant difference in effect on loss of renal concentrating power 
between patients with maximum levels of serum inorganic fluoride above or below $40 \mu \mathrm{M} / \mathrm{L}$.

Although one can be less confident on this point the evidence is strong that there will be a greater loss of concentrating power with methoxyflurane than with the control anaesthetic, over the whole range of durations $\mathrm{A}, \mathrm{B}$ and $\mathrm{C}$.

\section{Correlation of loss of kidney concentrating power with serum fluoride}

The mean and standard errors for serum inorganic fluoride levels for all groups on day $0,1,3$ and 5 are shown in Table II. These levels show a positive correlation with loss of kidney concentrating power. The most significant computer selected correlation was with serum fluorides on day 3 in Group A and on day 5 in Groups $B$ and $C$. The mean of serum inorganic fluoride in Group $C$ (day 1) (the highest of all findings) was approximately $52 \mu \mathrm{M} / \mathrm{L}$ (standard deviation 18). There was no significant correlation with the fact that the patient had serum fluorides below or above $40 \mu \mathrm{M} / \mathrm{L}$.

"Dosage" of methoxyflurane. This was not measured. The amount vaporized cannot be reliably related to the dose received by the patient. Even the percentage setting on the vaporizer cannot be definitely related to the concentration inspired by the patient, particularly with the high flows and semiclosed circuit used in our patients. Out of curiosity we did an analysis and found no significant correlation between the amount of methoxyflurane vaporized and loss of concentrating power, which was what we expected. It is interesting, however, to examine the amounts vaporized by 22 administrators and to compare them with Lowe's recommendations. In fact our anaesthetists generally were surprisingly close to the dose recommended (Table III). Most anaesthetists are without facilities to measure blood levels and the only guidelines at present are those of the manufacturer.

\section{Conclusion}

We are convinced by this study that the risk of a loss of kidney concentrating power occurring with methoxyflurane is high, compared with a nitrous-narcoticrelaxant technique. Children appear to tolerate it better. Methoxyflurane, if used in adults, should be confined to brief procedures only (probably less than 30 minutes). The risk of loss of concentrating power appears to increase with duration of exposure. There is a strong positive correlation between loss of concentrating power and serum inorganic fluoride levels, usually best demonstrated on the fifth post-operative day.

\section{ACKNOWLEDGMENTS}

Dr. Stanley Shapiro and Miss Joanne Swift, M.Sc., under Professor F.D.K. Liddell, Department of Epidemiology and Health, McGill University, did the statistical analyses and we are very grateful to them. We had great help and advice from Dr. Peter Cordy under the direction of Dr. Michael Kaye, Chief of the Division of Nephrology. Dr. Donald Douglas and his technicians in Toxicology, under Dr. Tonks, Head of Clinical Chemistry, were invaluable. Without the co-operation of the Head Nurses in the surgical wards this study would have been 
TABLE II

Serum Fluoride : $(\mu \mathrm{M} / \mathrm{L})$ Days $0,1,3$ and 5

(means and standard errors)

\begin{tabular}{cccc}
\hline & $\begin{array}{c}\text { Group A } \\
\text { and Standard } \\
\text { Error }\end{array}$ & $\begin{array}{c}\text { Group B } \\
\text { Meand Standard } \\
\text { Error }\end{array}$ & $\begin{array}{c}\text { Group C } \\
\text { Mean and Standard } \\
\text { Error }\end{array}$ \\
\hline 0 & $20.82(7.88)$ & $23.44(10.08)$ & $31.38(14.59)$ \\
1 & $40.81(21.04)$ & $46.48(25.02)$ & $52.15(18.38)$ \\
3 & $\mathbf{1 8 . 7 3 ( 1 4 . 2 9 )}$ & $27.33(14.87)$ & $33.90(26.80)$ \\
5 & $\mathbf{1 1 . 0 6 ( 1 0 . 4 0 )}$ & $12.15(7.99)$ & $20.67(20.30)$ \\
\hline
\end{tabular}

TABLE III

Total Dose of Methoxyflurane (Percentage $\times$ Time) Recommended and USED (mean and standard errors)

\begin{tabular}{lcrrrr}
\hline \hline & Group A & Group B & Group C \\
\hline $\begin{array}{l}\text { Recommended } \\
\text { Used }\end{array}$ & $\mathbf{1 6 7 2 . 6}(60.18)$ & $2425.68(65.16)$ & $3409.75(152.78)$ \\
\hline
\end{tabular}

impossible. Abbott Laboratories and Ayerst Laboratories provided generous support for this study.

\section{Footnote}

Mechanics of the regression analysis. It was thought that the decrease in urine osmolality might depend on the size of initial urine osmolality on day 0 . Thus urine osmolality on day 0 was used as a standardizing variable in the regression analysis.

The notation used for the variables in the regression is as follows:

UROSO = urine osmolality on day 0

UROS5 = urine osmolality on day 5

DIFF $=$ UROS0-UROS5

SEFLO = serum fluoride level on day 0 (end of surgery)

DEFLl $=$ serum fluoride level on day 1

SEFL3 = serum fluoride level on day 3

SEFL5 = serum fuoride level on day 5

Dose = "dosage of methoxyflurane used" ( actually the product of concentration inspired and time).

The stepwise regression was carried out in the following way: UROS0 was forced in at the first step as a standardising variable. This was done to remove any differences in loss of concentrating power which could be due to differences in initial urine osmolality.

At the next step the variable explaining most of the remaining variation was chosen. This procedure was continued until no significant amount of variation can be explained by the remaining variables.

\section{Results of analyses}

Group A. At step 1 the variable UROSO is forced in. R2 (the percentage of variation) is 0.16 . At step 2 the variable with the highest partial correlation, i.e. the variable which explains the largest amount of remaining variation is SEFL3. This means that there is a relationship between the variables DIFF and SEFL3 after removing the effect of initial urine osmolality. $R^{2}$, the percentage of variation explained by the two variables UROSO and SEFL3 is 0.30 . It has increased by 0.14 with the introduction of SEFL3. The process terminates as no other variable will explain a significant amount of the remaining variation.

Group B. At step 1, the variable UROS0 is forced in. $\mathrm{R}^{2}$ is 0.18 .

At step 2, the variable with the highest partial correlation is SEFL5. $\mathrm{R}^{2}$ is 0.40 . It has decreased 
by 0.22 with the introduction of SEFL5. The process terminates as no other variable will explain a significant amount of the remaining variation.

Group $C$. At step 1 , the variable UROSO is forced in. $\mathrm{R}^{2}=0.01$, and not significant. In this group initial urine osmolality does not explain any of the variation in loss of concentrating power.

At step 2 , the variable with the highest partial correlation is SEFL5. $\mathrm{R}^{2}$ is 0.32 . It has increased by 0.31 with the introduction of SEFL5.

At step 3, the variable with the highest partial correlation is SEFL0.

However, this correlation is negative. It is the correlation between SELF0 and DIFF after the effect of the variables UROSO and SEFL5 have been removed. This makes it rather difficult to interpret. $R^{2}$ is 0.47 . It has increased by 0.15 with the introduction of SEFLO.

The process terminates as no other variables will explain significant amount of the remaining variation.

Conclusion. In the three duration groups A, B and C, we found a significant positive correlation between loss of kidney concentrating power (DIFF) and one of the serum fluorides. In group A SEFL3 had the highest partial correlation; in groups B and C SEFL5 did. It should be pointed out, however, that in group A the partial correlation for SEFL5 is only slightly smaller than that for SEFL3.

It also seems that the relationship of DIFF to the serum fluoride chosen after standardising the UROSO improves slightly as the duration increases. The increase in $\mathrm{R}^{2}$ due to the serum fluoride is largest in group $C$.

Comparing loss of kidney concentrating power in the methoxyflurane and control groups. As before on the hypothesis that loss of kidney concentrating power was related to initial urine osmolality, we felt it necessary to standardise for UROSO before comparing to groups. We therefore ran a regression between the variables DIFF and UROSO for all 149 patients yielding the following regression equation:

$\mathrm{DIFF}=-241.023+0.376$ UROS0

The squared correlation coefficient $R^{2}$ between DIFF and UROSO was 0.32 . That is 32 per cent of the variation in the variable DIFF could be explained by differences in UROSO.

We calculated the residuals about the regression line as follows:

RES $=$ DIFF + 241.023 - 0.376 UROSO

We then performed a two factor analysis of variance on the calculated residuals: Drug being one factor, duration the other factor.

Three hypotheses could be tested:

$H_{0} \mathbf{l}$ : There is no difference in loss of kidney concentrating power between the drug and the control group

$\mathrm{H}_{0} 2$ : there is no difference in loss of kidney concentrating power between the three duration groups,

$\mathrm{H}_{0} 3$ : there is no interaction effect. That is the differences between drug and control groups does not depend on duration.

The following results were found:

The test statistic for $H_{0} l$ is: $F_{1}, 143=3.57$, the probability associated with this value is between 0.05 and $0.10(=6.5 \%)(0.065)$.

The test statistic for $\mathrm{H}_{0} 2$ is $\mathrm{F}_{2}, 143=3.40$, the probability associated with this value is less than 0.05 ( $=3.9 \%)(0.039)$.

The test statistic for $\mathrm{H}_{0} 3$ is: $\mathrm{F}_{3}, 143=1.78$, the probability associated with this value is greater than $0.10(=19 \%)(0.19)$

\section{Loss of Concentrating Power within Groups $A, B$ and $C$}

$\begin{array}{cccc}\text { Group } & \begin{array}{c}\text { Difference in mean loss } \\ \text { of concentrating power } \\ \text { (MXF-CONTROL) }\end{array} & \begin{array}{c}\text { Simultaneous } 95 \text { per cent C.I. for } \\ \text { differences in mean loss of } \\ \text { concentrating power }\end{array} \\ \text { Group A } & 71.43 & (-37.55, & 179.41) \\ \text { Group B } & -18.88 & (-127.86, & 90.10) \\ \text { Group C } & 94.73 & (-14.25, & 203.71)\end{array}$

The intervals should be interpreted in the following manner: the probability is 0.95 that all the intervals simultaneously embrace their respective true values of the difference in mean loss of concentrating power. As the intervals provide protection against making any false statement (out of the three) they will necessarily be wider than the corresponding set of three nonsimultaneous intervals. 


\section{RÉSUMÉ}

Cette étude conclut que le risque de perte de pouvoir de concentration rénale après usage de methozyflurane est élevé par comparaison à une technique utilisant le protoxyde d'azote avec un narcotique et un relaxant.

Les enfants semblent moins touchés que les adultes chez lesquels on devrait restreindre son usage aux interventions de courte durée (moins de 30 minutes). Le risque de perte du pouvoir de concentration rénale semble augmenter avec la durée de l'anesthésie au methoxyflurane.

Une corrélation fortement positive existe entre la perte du pouvoir de concentration rénale et les taux sériques de fluor inorganique, corrélation démontrable en particulier au cinquième jour post-opératoire.

\section{REFERENCES}

1. Crandell, W.B., Pappen, S.F., \& MacDonald, A. Nephrotoxicity associated with methoxyflurane anesthesia. Anesthesiology 27: 591-607 (1966).

2. Mazze, R.L., Shue, G.R., \& Jackson, S.H. Renal dysfunction associated with methoxyflurane anesthesia. A randomized, prospective clinical evaluation. Journal of the American Medical Association 216: 278-288 (1971).

3. Hethick, W.D., Wolfson, B., Garcia, D.A., \& Siker, E.S. Renal responses to light methoxyflurane anesthesia. Anesthesiology 38: 30-37 (1973).

4. Dose-regulated Penthrane administration, Abbott Laboratories Limited, October 1971.

5. Golpembers, L. Tratamiento de la enfermadad de basedow y del hipertiroidismo por fluor. Rev. Soc. Med. Int. Soc. Tisiolog. 6: 217-242 (1931).

6. Taves, D.R., Fry, B.W., Freeman, R.B., \& Gilllies, A.J. Toxicity following methoxyflurane anesthesia. II. Fluoride concentrations in nephrotoxicity. JAMA 214: 91-95 (1970).

7. Whitford, G.M. \& TAves, D.R. Fluoride-induced diuresis: plasma concentrations in the rat. Proceedings of the Society for Experimental Biology and Medicine. 137: 458-460 (1971).

8. Bond, A.M. \& Murray, M.M. Kidney function and structure in chronic fluorosis. British Journal of Experimental Pathology 33: 168-176 (1952).

9. Fencuson, D.B. Effects of low doses of fluoride on serum proteins and a serum enzyme in man. Nature New Biology 231; 159-160 (1971). 